\title{
THE STUDY OF THE TROPICAL CYCLONE TRACKS OVER THE WESTERN INDIAN OCEAN UP TO THE MOKRAN REGION AND OMAN SEA
}

\author{
Mojtaba ZOLJOODI*, A. DIDEVARASL ${ }^{\dagger}$
}

\begin{abstract}
Cyclones are considered one of the most dangerous meteorological phenomena of the tropical region. Behavior of tropical cyclone trajectories needs to be better understood in order to find predictable aspects of landfall potentially. This research aims to analyze the cyclone tracks statistically and then study of the associated meteorological effects of Gonu cyclone in June 2007 as an example. Using the cluster analysis (K-mean method) 5 principal clusters have been derived and spatial - temporal studies including the monthly variation of cyclone trajectories and their intensity and frequencies are performed. The $4^{\text {th }}$ cluster indicated more spatial variability and expansion $\left(4^{\circ}-31^{\circ} \mathrm{N}\right.$ and $\left.48.5^{\circ}-78^{\circ} \mathrm{E}\right)$. The second cluster showed the highest frequency with 349 events as well as the highest maximum intensity and standard deviation of $235.2 \mathrm{~km} / \mathrm{h}$ and $47.96 \mathrm{~km} / \mathrm{h}$ respectively. During 17 June 2007, the Gonu super cyclone traversed the Arabian Sea and reached the Iranian southern shores. In this 7-day period the daily composite maps of different atmospheric levels showed that by intensifying of Gonu cyclone the axis of subtropical high pressures in the lower levels moved to the east and in the 500hp level they moved to the northward over the study region.
\end{abstract}

Key words: Tropical Cyclone Tracks, Arabian Sea, Mokran region, Cluster analysis, Atmospheric conditions

\section{INTRODUCTION}

Tropical cyclones are low pressure systems that have thunderstorm activity and rotate counterclockwise. Tropical cyclones form over all tropical oceanic areas except the South Atlantic and the Southeast Pacific. A tropical cyclone (TC) is a synoptic-scale to meso-scale low-pressure system over tropical or subtropical waters with organized convection and definite cyclonic surface wind circulation. TCs have significant impacts on the weather and climate of tropical countries (Riehl, 1979). Their frequency and intensity in the North Indian Ocean is very important for the maritime regions of South Asia.

Tropical cyclones imply significant threat to communities that lie in their paths, so improving our understanding of TC formation, track and intensity is of significant importance. Annually, about 30\% of global TCs form in the Southern

\footnotetext{
* Iranian National Institute for Oceanography and Atmospheric Sciences, Tehran, Iran.zoljoodi@inio.ac.ir

${ }^{\dagger}$ Iranian National Institute for Oceanography and Atmospheric Sciences, Tehran, Iran. E-mail: ali_didehvar714@yahoo.com
} 
Hemisphere (Neumann et al. 1993), spanning a large area from the western Indian Ocean to the central Pacific and covering three TC basins: the southwest Indian Ocean (West of 90E), the Australian Region (90-160E) and the South Pacific Ocean (East of 160E). Genesis location of TCs can be linked to the seasonality, sea surface temperature, wind shear, and position of the initial disturbance (Gray 1968; Henderson-Sellers et al. 1998).

According to a research developed by Evan and Camargo (2011), November cyclones primarily form during periods when the Bay of Bengal experiences a broad region of high sea level pressure, implying that November storms form in either the Arabian Sea or the Bay of Bengal but not in both during the same year. Additionally, the analysis of changes in a genesis potential index suggests that long-term variability in the potential for a storm to form is dictated by changes in mid level moisture. Landfall and the intensity of the storm at landfall are also associated with genesis location and track shape (Camargo et al. 2007).

Ramsay et al. (2011) performed an investigation on a probabilistic clustering method to describe various aspects of tropical cyclone tracks in the southern hemisphere, they found ENSO has a significant effect on mean genesis location in three clusters with TCs forming further equator-ward during El Nino (La Nina) in addition to large shifts in mean longitude. They found that the Madden Julian Oscillation has a strong influence on TC genesis in all clusters. Cluster analysis provides a way to objectively classify storms in a given ocean basin into subcategories depending on geographical properties of the storms (e.g., genesis, track location, and shape). Such classification can become useful for building predictive understanding on climatic time scales.

The K-means method (MacQueen 1967) is a common clustering method that has been used both with tropical and extra-tropical cyclone tracks. In the present investigation we have considered initially the TC frequencies in monthly and yearly scales over the western Indian Ocean and the Arabian Sea, and then using the k-means method the tropical cyclones have been clustered based on their positions $(\mathrm{x}, \mathrm{y})$ into 5 main groups. They have been analyzed regarding the TCs intensities, and then we studied the associated physical and dynamical parameters in the atmospheric levels during the Gonu super cyclone (1-7 June 2007) over the study region. All TC data sets are gathered from The International Best Track Archive for Climate Stewardship in 6-hourly resolution over the study area in 1990-2013.

\section{RESULTS}

\subsection{Statistical analysis}

The tropical cyclone (TC) frequencies showed an annual average of TC events about 44 in the investigated 24-year period (1990-2013), and the maximum and minimum values were 123 in 2004 and 8 in 2000 respectively. The interannual (seasonal) distribution of TC frequency confirmed that the tropical storms are active during per and post monsoon periods over the Arabian Sea and Western 
Indian Ocean (Fig.1). During pre- and post-monsoon periods of May-June and October-November respectively, the equatorial position of the Somali Jet and broad region of positive vorticity values, coupled with warmer regional ocean temperatures provide a larger favorable region for storm development. In winter months because existing of the minimum temperature on the sea surface there is not sufficient condition to storm genesis. Monthly tropical storm duration indicated the maximum values of 14, 11 and 9 days in November 2011, October 1998 and June 2007 respectively. In total, stormy days duration over post-monsoon period could be higher than per-monsoon, as in October and November the two-month average of long term storm duration was about 50 days, while for May and June it is reached about 41 days (Fig.1).
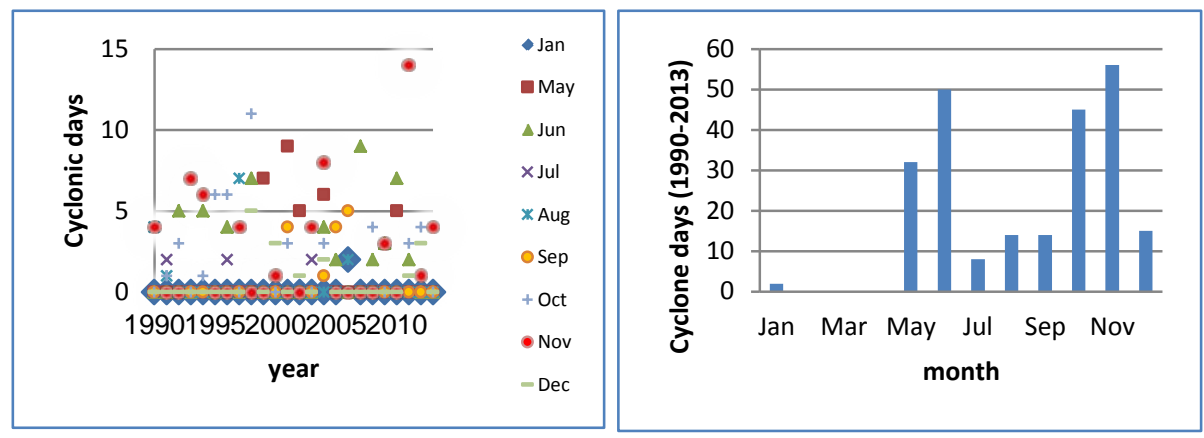

Fig. 1. Monthly scatter plot of cyclonic storm days (CS-days=storm duration) over the Arabian Sea for each year in the period 1990-2013 (left panel), and a long term monthly distribution of cyclonic days over the study area (right panel).

A long term spatial intensity analysis of the TC records illustrated the most severe storms (by 148.16-235.2 km/h) in two tracks with opposite directions over the study area, as the both of them originated from the same position as follows: $15^{\circ}-20^{\circ} \mathrm{N}$ and $65^{\circ}-70^{\circ} \mathrm{E}$, and then the storms move on in two separate tracks toward northwest and northeast. In the case of land-falling they may hit the eastern shores of Oman (by the northwestern track) and the northwestern shores of India and southern Pakistani beaches (by the northeastern track). Surrounding the mentioned two main tracks there are the relatively weak storms (by 92.6-148.16 $\mathrm{km} / \mathrm{h}$ ) and also over an area shaped as a triangular among them, with front angle is oriented southwards, and the base line set northward we found a calm region with no storms or disturbances (it is shown with dark line on Fig. 2.).

Cluster analysis classified the TC dataset into 5 different groups based on the location variances of each group. The cluster 2 indicates the highest TC frequency with 349 events and in the next ranks the clusters 1, 5, 4 and 3 are represented by 265, 190, 145 and 113 events, respectively. In an inter-annual outlook, for all clusters in winter months and partially in summer there is the lowest cyclone frequency, whiles the highest ones are found for cluster 1 at October (88 events), cluster 2 and 4 at May (101 and 36 events), cluster 3 and 5 at November (61 and 77 events). Regarding the monthly median values it is 
remarkable that for the clusters 1,3 and 5 the main portion of TC frequency has been happened in autumn season, but for the clusters 2 and 4 they have been distributed equally in the first and second half of year (Table 1).
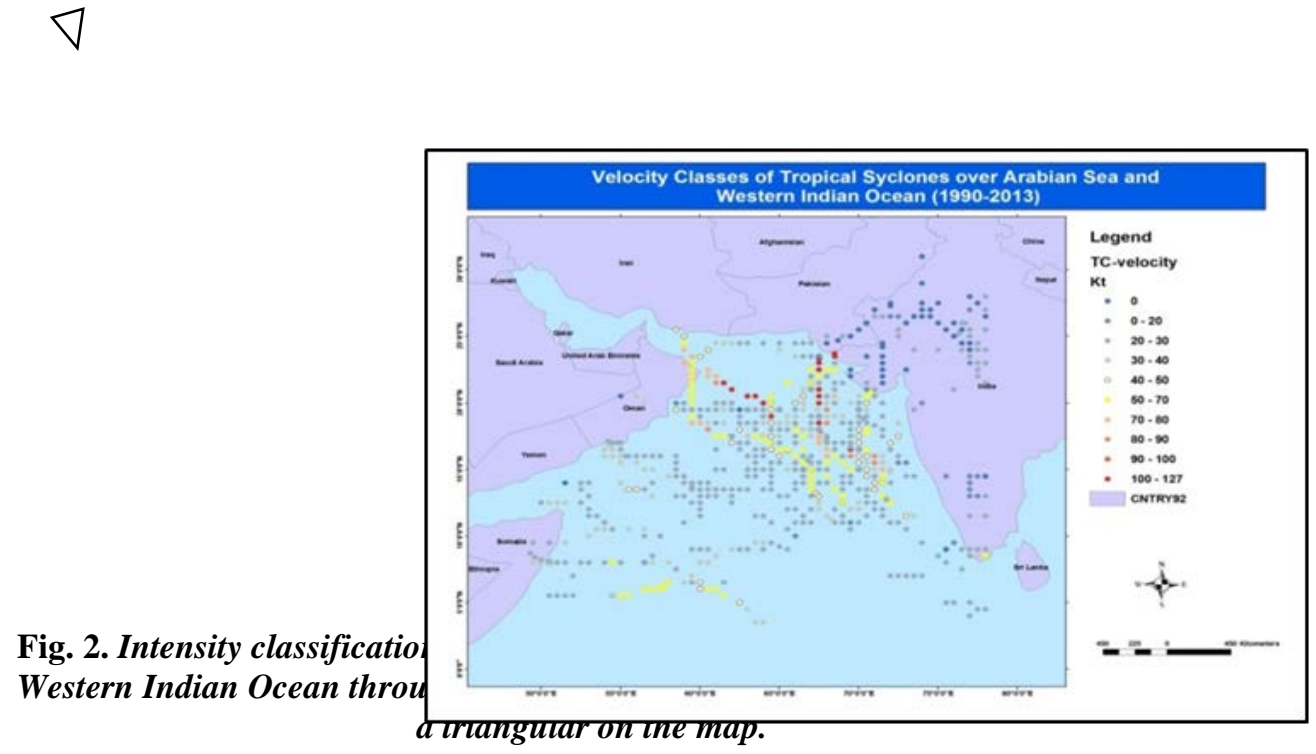

Table 1. Tropical cyclone frequency, monthly min and max TC events and median for each cluster

\begin{tabular}{|c|c|c|c|c|}
\hline Variable / & $\begin{array}{l}\text { Total TC } \\
\text { frequency }\end{array}$ & $\begin{array}{l}\text { Monthly min } \\
\text { frequency }\end{array}$ & $\begin{array}{l}\text { Monthly max } \\
\text { frequency }\end{array}$ & median \\
\hline 1 & 265 & Jan-Apr (0) & Oct (88) & Oct \\
\hline 2 & 349 & Jan-Apr (0) & May (101) & June \\
\hline 3 & 113 & Jan-Apr\&Aug(0) & Nov (61) & Nov \\
\hline 4 & 145 & Feb-Apr\&Jul(0) & May (36) & Jul \\
\hline 5 & 190 & $\begin{array}{l}\text { Feb-Apr\&Jul-Aug } \\
\text { (0) }\end{array}$ & Nov (77) & Oct \\
\hline
\end{tabular}

Table 2 presents the mean genesis location and the range of those positions along with the variance of TCs based on their $\mathrm{x}$ and $\mathrm{y}$ for each cluster. The mean values of TC positions show the cluster 4 formed the farthest North and East of all the clusters with the highest variability regarding its ranges of genesis location in both latitude and longitude. The cyclones in cluster 3 are shaped in farthest South and west averagely, along with the highest variability in longitude. The cluster 5 placed in a middle position among these 5 clusters (about $15^{\circ} \mathrm{N}$ and $62^{\circ} \mathrm{E}$ ) with the second highest variability in longitude and latitude after the $4^{\text {th }}$ cluster (Table 2).

The actual output of the K-means clustering is groups of centroid locations and directional variance. Clear separation of the clusters can be seen in the groupings of the centroids and slope and size of the variance ellipses. The clusters1, 2 and 5 sited almost in the central position with the stretched variance 
ellipses along the longitude, although the second cluster has a more tilted axis. The cluster 4 has the largest rounded ellipse with a positive tilt and the farthest north location. Finally the farthest southern cluster 3 with the variance ellipse elongated along the $\mathrm{x}$ axis (Fig. 3).

Table 2. Variance and mean values of $x$ and $y$ along with the range of tropical cyclone genesis locations for each cluster

\begin{tabular}{|c|c|c|c|c|c|c|}
\hline Variable & $\begin{array}{l}\text { Variance } \\
\text { Lat }\end{array}$ & $\begin{array}{l}\text { Variance } \\
\text { Lon }\end{array}$ & Mean lat & Mean lon & $\begin{array}{l}\text { Genesis } \\
\text { range lat }\end{array}$ & $\begin{array}{l}\text { Genesis } \\
\text { range lon }\end{array}$ \\
\hline 1 & 14.66 & 24.43 & 16.79 & 66.94 & 24.5-3.5 & $78-51.5$ \\
\hline 2 & 14.41 & 17.85 & 17.69 & 67.6 & $27.5-7$ & $78-54$ \\
\hline 3 & 14.58 & 54.99 & 11.51 & 58.35 & $20.5-5.5$ & $78-49.3$ \\
\hline 4 & 57.38 & 50.17 & 18.17 & 69.93 & $31-4$ & $78-48.5$ \\
\hline 5 & 29.89 & 37.45 & 15.48 & 62.62 & $25.5-5$ & $77.5-50$ \\
\hline
\end{tabular}

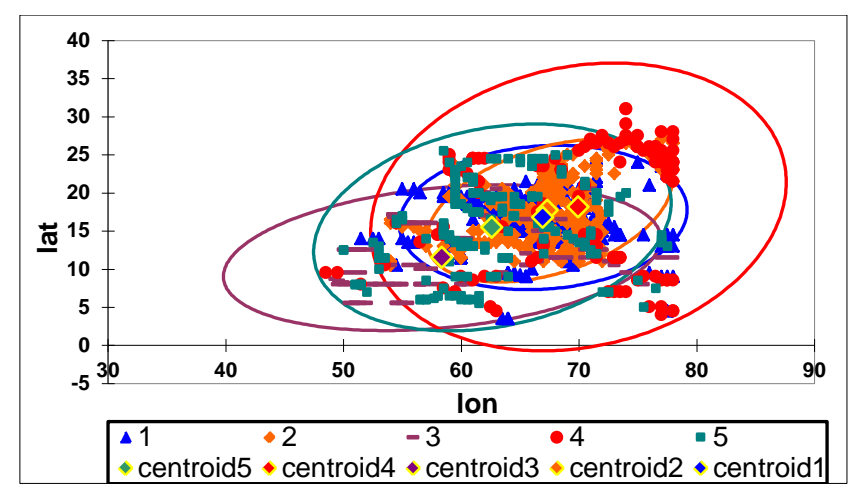

Fig. 3. Centroid locations (asterisks) for the 5 clusters. The mean centroid value is marked bigger by colored diamond, and the mean variance ellipse with colored lines

\section{$2.2 \quad$ Intensity variability of the tropical cyclones}

Intensity analysis of the TCs has been performed using the wind speed data sets (in knot/hour) for each cluster. All 5 clusters except for the $4^{\text {th }}$ cluster revealed that $50 \%$ of the TCs included the intensity more than or equal to $55.56 \mathrm{~km} / \mathrm{h}$, regarding their obtained median values. As the second cluster has the highest storm frequencies, the maximum wind speeds $(235.2 \mathrm{~km} / \mathrm{h})$ as well as the highest standard deviation rank $(48 \mathrm{~km} / \mathrm{h})$ and the highest mean value $(72.52 \mathrm{~km} / \mathrm{h})$ are found in this cluster. Also the skewness test (SKEW) indicated the positive rates which confirm the departure of the TC intensities toward more positive values from the average in the all clusters. The highest SKEW rate (2.95) pertained to the third cluster, as the minimum wind speed $(46.3 \mathrm{~km} / \mathrm{h})$ was the closest to the average value $(62.96 \mathrm{~km} / \mathrm{h})$ in this cluster, while the maximum wind speed is recorded $212.98 \mathrm{~km} / \mathrm{h}$ and so the positive distance from the average value is considered remarkable (Table 3). 
Table 3. Statistical characteristics of the tropical cyclones intensity for 5 clusters over the Arabian Sea during 1980-2013.

\begin{tabular}{|c|l|l|c|c|c|c|c|}
\hline Variable/ & $\begin{array}{l}\text { Total } \\
\text { frequency }\end{array}$ & $\begin{array}{l}\text { Minimum } \\
\text { intensity } \\
(\mathrm{km} / \mathrm{h})\end{array}$ & $\begin{array}{l}\text { Maximum } \\
\text { intensity }\end{array}$ & $\begin{array}{l}\text { Median } \\
\text { Intensity }\end{array}$ & $\begin{array}{l}\text { Mean } \\
\text { intensity }\end{array}$ & SKEW & $\begin{array}{l}\text { Standard } \\
\text { deviation } \\
\text { of } \\
\text { intensity }\end{array}$ \\
\hline 1 & 265 & 0 & 194.46 & 55.56 & 67.39 & 1.44 & 35.68 \\
\hline 2 & 349 & 0 & 235.2 & 55.56 & 72.52 & 1.43 & 48 \\
\hline 3 & 113 & 46.3 & 212.98 & 55.56 & 64.39 & 2.95 & 22.94 \\
\hline 4 & 145 & 0 & 188.9 & 46.3 & 52.89 & 0.58 & 34.8 \\
\hline 5 & 190 & 0 & 212.98 & 55.56 & 67.87 & 1.69 & 34.7 \\
\hline
\end{tabular}

\subsection{Synoptic analysis}

In this section we considered the Gonu tropical cyclone which has been happened in 1-7 June 2007 over the study area. To evaluate the physical and dynamical variability of the atmosphere during the Gonu cyclone, the anomalies of sea level pressure, geopotential height, air temperature, relative humidity, vertical velocity and wind vector have been analyzed at different atmospheric levels as follows:

The maximum negative anomaly of SLP (sea level pressure) with -4 to $5 \mathrm{mb}$ was prevailed over the central Arabian Sea in 3-5 June.

The minimum pressure in the eye of cyclone is calculated to be about 898hPa using the images of Metosat satellite.

The geopotential height at500hPa level in 5-6 June showed a $-40 \mathrm{~m}$ anomaly in the east of Oman Gulf and Mokran shores that indicated the northward migration of Subtropical High Pressure (STHP) and on 6 June this anomaly even increased to $-60 \mathrm{~m}$. The vertical velocity parameter at $500 \mathrm{hPa}$ level in 5 June showed the vertical motions anomaly about $-0.15 \mathrm{hPa} / \mathrm{s}$ over the east and southeast of Oman Gulf. In 6-7 June these conditions intensified up to -0.18 and $-0.2 \mathrm{hPa} / \mathrm{s}$ and dominated toward north over the Oman Sea which indicated the severe convective activities.

The air temperature at $850 \mathrm{hPa}$ atmospheric level illustrated a decrease, as the anomaly values during 4-7 June were about -4 to $-8^{\circ} \mathrm{K}$ over the study region because of a severe condensations in this level and then releasing of latent energy in upper level by temperature increase at $500 \mathrm{hPa}$. By the injection of the moist air from the sea surface to the region in 6 June, the humidity increased by $30 \%$ in comparison with the normal period and it extended toward north over the Iranian interior territory.

Over the region, the wind velocity increased more than double the normal average. The winds with over $12 \mathrm{~m} / \mathrm{s}$ speed dominated over the southern parts of Oman Sea and the central parts of Arabian Sea in 5 June and gradually moved up towards the north parts of Oman sea and Iranian shores by decreasing the wind speed around $7-8 \mathrm{~m} / \mathrm{s}$ in $8 \mathrm{June}$, and consequently the huge waves attacked the shoreline and the wave heights in some cases were reported to be more than5-6 meters (Fig. 4). 


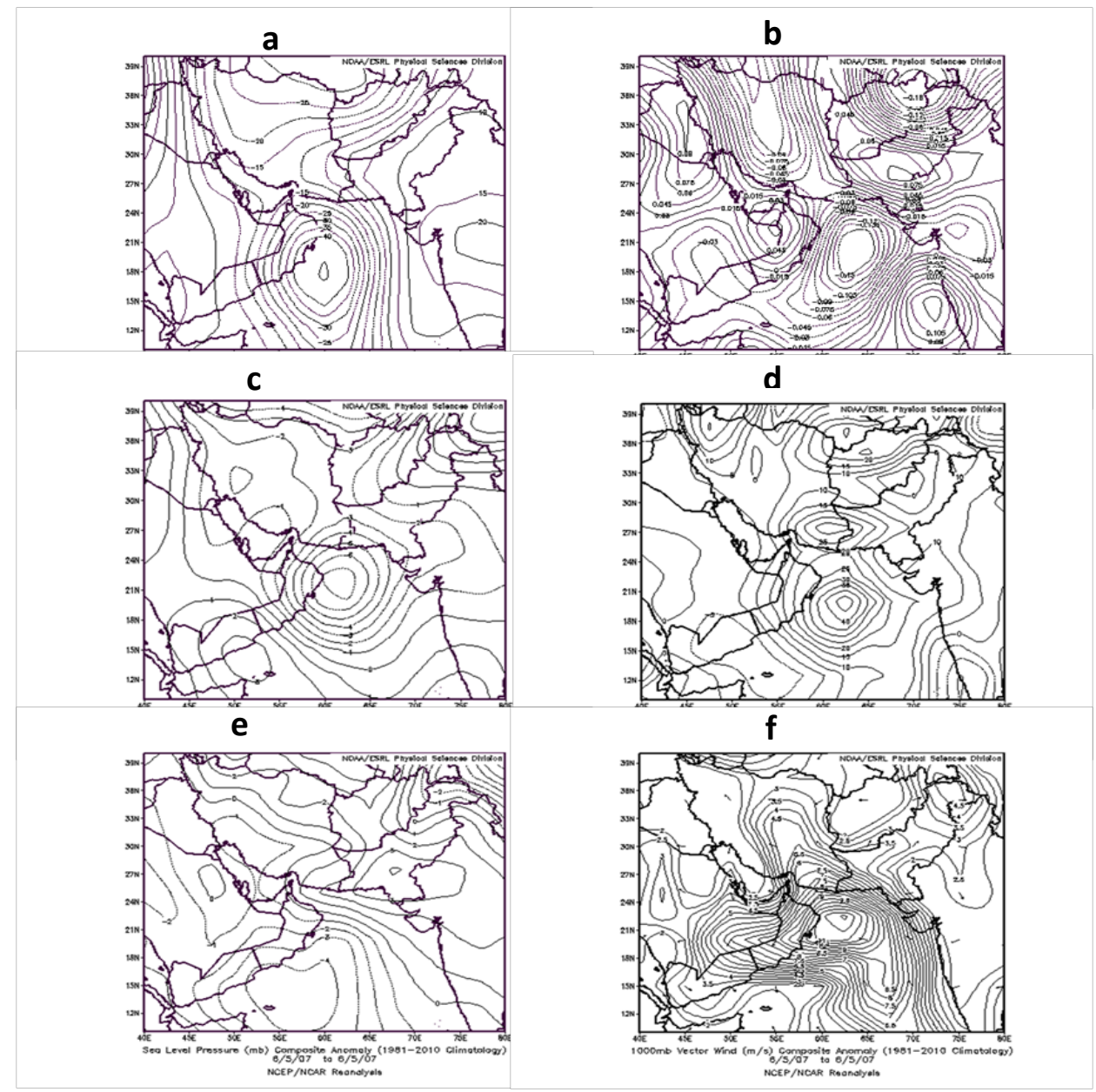

Fig. 4. Daily composite anomaly maps (1981-2010), the example for June 5, 2007. a) $500 \mathrm{mb}$ geopotential height, b) $500 \mathrm{mb}$ vertical wind speed, c) $850 \mathrm{mb}$ air temperature, d) $850 \mathrm{mb}$ relative humidity, e) sea level pressure, f) $1000 \mathrm{mb}$ wind speed.

\section{CONCLUSION}

A long term statistical analysis illustrated that the TC frequency has been raised through a 7-year period of 1998-2004 (up to 123 events in 2004) over the study area. In an inter-annual outlook the tropical cyclones were considerably frequentative during per and post monsoon months, as the equatorial position of the Somali Jet and broad region of positive vorticity values that are coupled with warmer regional ocean temperatures provide a larger favorable region for storm development over the Arabian Sea.

Spatially the TC records illustrated that the most severe storms (by 148.16$235.2 \mathrm{~km} / \mathrm{h}$ ) were found in two tracks with opposite directions, as the both of them originated from the same position as follows, $15^{\circ}-20^{\circ} \mathrm{N}$ and $65^{\circ}-70^{\circ} \mathrm{E}$ and then the 
storms moved on in two separate tracks toward northwest and northeast of the Arabian Sea.

The K-means cluster method classified the TC records into 5 groups revealing that for the clusters 1,3 and 5 the main portion of TC frequency has been happened in autumn season, but for the clusters 2 and 4 they have been distributed equally in the first and second half of year.

The variance ellipses showed the clusters 1,2 and 5 were placed over a central position of the study area with the stretched variance ellipses along the longitude axis mostly. The cluster 4 has been considered the largest rounded ellipse and the farthest northern position. While the farthest southern cluster 3 with the variance ellipse elongated along the longitude axis. All 5 clusters except for the cluster 4 confirmed that $50 \%$ of the TCs had the intensity more than or equal to $55.56 \mathrm{~km} / \mathrm{h}$.

The skewness test illustrated a tendency of TC intensities toward more positive values from the average in the all clusters. The results of synoptic analysis by the daily composite maps in June 1-7, 2007 illustrated that by intensifying the Gonu storm, the axis of subtropical high pressures in the lower levels of atmosphere moved toward the east, and in the mid-levels of atmosphere it moved toward the north. This replacement provided the suitable conditions to form an intense convection and tropical cyclone.

\section{REFERENCES}

1. Camargo S. J. , A. W. Robertson, S. J. Gaffney, P. Smyth, and M. Ghil, (2007), Cluster analysis of tropical cyclone tracks. Part I: General properties .J. Climate,20,3635-3653.

2. Gray, W. M., (1968), Global view of the origin of tropical disturbances and storms. Mon. Wea. Rev., 96, 669-697.

3. Evan T. A. and Camargo S. J., (2011), A Climatology of Arabian Sea Cyclonic Storms., Journal of Climate , Volume 4, DOI: 10.1175/2010JCLI3611.1.

4. Henderson-Sellers, A., et al., (1998), Tropical cyclones and global climate change: A post-IPCC assessment. Bull. Amer. Meteor. Soc., 79, 19-38.

5. MacQueen, J., (1967), Some methods for classification and analysis of multivariate observations. Proc. Fifth Berkeley Symp. On Mathematical Statistics and Probability, Berkeley, CA, University of California, 281-297.

6. Neumann, C. J., B. R. Jarvinen, C. J. McAdie, and J. D. Elms, (1993), Tropical Cyclones of the North Atlantic Ocean 1871-1992., National Climate Data CenterNational Hurricane Center, 193 pp.

7. Ramsay. H.A., Suzana J. Camargo and Daehyun Kim (2011), Cluster analysis of tropical cyclone tracks in the Southern Hemisphere., Clim Dyn (2012) 39:897917. DOI 10.1007/s00382-011-1225-8.

8. Riehl. H., (1979), Climate and weather in the tropics, Academic Press, London, No. of pages: 611. ISBN 0.12.588180.0. 